\title{
VERTEBRAL HYDATIDOSIS: BIBLIOGRAPHICAL REVIEW AND CLINICAL CASE REPORT
}

\author{
HIDATIDOSE VERTEBRAL: REVISÃO BIBLIOGRÁFICA E RELATO DE CASO CLÍNICO \\ HIDATIDOSIS VERTEBRAL: REVISIÓN BIBLIOGRÁFICA Y REPORTE DE CASO CLÍNICO \\ Juan Manuel Velasco, ${ }^{1}$ Santiago Sapriza, ${ }^{1}$ Nicolás Galli, ${ }^{1}$ Fernando Garcia ${ }^{1}$ \\ 1. Center for Spinal Deformities - CE.DEF.CO, Montevideo, Uruguay.
}

\begin{abstract}
We will present a literature review of the vertebral location of hydatidosis. It is a rare, locally aggressive condition with a high recurrence rate that requires clinical treatment (antihelminthic drugs) and surgery, with decompression of the spinal canal. We report a case with more than 11 years of follow-up, which required surgical treatment on 4 occasions. Level of Evidence V; Therapeutic-investigational study of treatment results.
\end{abstract}

Keywords: Hydatidosis; Recurrence; Surgical procedures, operative.

\section{RESUMO}

Estaremos apresentando uma revisão bibliográfica da localização vertebral da hidatidose, patologia de baixa frequência, localmente agressiva, com alta taxa de recorrência, que requer tratamento médico (antihelmíntico) e cirúrgico com a descompressão do canal espinhal. Nós reportamos um caso com seguimentos de mais de 11 anos, que exigiu tratamento cirúrgico em 4 oportunidades. Nível de Evidência V; Estudo terapêutico - investigação dos resultados do tratamento.

Descritores: Hididatidose; Recidiva; Procedimentos cirúrgicos operatórios

\section{RESUMEN}

Presentaremos una revisión bibliográfica de la localización vertebral de la hidatidosis. Es una patología poco frecuente, agresiva localmente, con alta tasa de recurrencia y que requiere tratamiento clínico (medicaciones antihelmínticas) y quirúrgico, con descompresión del canal vertebral. Mostramos un caso clínico con seguimiento de más de 11 años, el que requirió tratamiento quirúrgico en 4 oportunidades. Nivel de Evidencia V; Estudio terapéutico-investigación de los resultados del tratamiento.

Descriptores: Hidatidosis; Recurrencia; Procedimientos quirúrgicos operativos.

\section{INTRODUCTION}

Human hydatidosis is a zoonosis caused by larval forms of tapeworms of the genus Echinococcus that are found in the small intestine of carnivorous animals. Although several species of Echinococcus have been described, only two of them, E. granulosus and $\mathrm{E}$. multilocularis, are pathogens for humans.

Their life cycle includes a larval phase that usually occurs in cows, pigs, and other herbivores, and an adult or tapeworm phase that usually appears in dogs and other carnivorous animals. Humans are considered an accidental intermediary in the life cycle of Equinococci, in which the hydatid cyst develops.

Hydatidosis has a universal distribution and is endemic to Australia, South America, and northeastern Africa. In Uruguay, hydatidosis is an endemic disease with an estimated 8,000 to 10,000 Uruguayans who are carriers of this pathology and do not know it. ${ }^{1}$

Infestation with hydatidosis is mainly located in the liver and lungs. ${ }^{2}$ Bone hydatidosis occurs in between $0.5 \%$ and $2 \%$ of all cases, located in the vertebrae in $50 \%$ of all musculoskeletal hydatidoses, followed by other locations such as the pelvis and the long bones. ${ }^{3}$

In endemic zones, vertebral hydatidosis, although a rare pathology, should be considered in all cases of spinal cord compression with cystic images. Due to its anatomopathological characteristics, it often presents clinically as pain and neurological compromise. Imaging is often nonspecific, although MRI reveals highly suggestive characteristics of this pathology. The treatment of this illness should be approached by a multidisciplinary team. In his classic work of 1948, Felix Dévé, who played a key role in describing this pathology, called it "white cancer", alluding to its aggressive behavior, high rate of recurrence, and poor prognosis. ${ }^{4}$

There are multiple techniques and procedures described according to the vertebral topography of this pathology, but surgical treatment is rarely curative. The prognosis is usually poor with a high recurrence rate.

\section{CLINICAL CASE REPORT}

This is the case report of a male patient, 52 years of age, from a rural area without a personal history of previous pathologies of note.

In June 2006, he entered the service presenting a profile of paraparesis of the lower limbs and paresthesias, accompanied by sphincter changes with diminished bilateral osteotendinous reflexes. The imaging revealed a voluminous right paravertebral multiseptated cystic lesion at levels T9 and T10 in close proximity to the vertebral bodies, which presented morphological changes. Compression of the canal by cystic formations that compress the dural sac was evident. (Figure 1)

Emergency surgery was performed by a team of traumatologists specialized in spine surgery and thoracic surgeons, with the patient in left lateral decubitus, a thoraco-phreno-laparatomy approach was performed. A large, $10 \times 8$ centimeter, right paravertebral cyst with an 
intravertebral extension and multiple smaller vesicles were resected. Subsequently, he was treated with antihelminthics for an unknown period of time. There were no complications and his symptoms reversed completely. The anatomopathological study confirmed the clinical suspicions.

In 2006 he underwent surgery for a hepatic hydatid cyst.

In April 2010, he had a progressive clinical picture characterized by intense thoracolumbar pain and sensory changes in the region of the intercostal nerves including severe paraparesis. The MRI revealed a right paravertebral multiseptated cystic formation, 30 by 20 $\mathrm{mm}$ in size, at level T9 and T10, hyperintense in T2 and hypointense in T1, which was invading the canal through the left neuroforamen and compressing the spinal cord. (Figure 2) A posterior approach laminectomy of T9 and part of T10 was performed, the dural sac was released, and the cysts and hydatid membranes were resected. Hydrogen peroxide was used, letting it act for several minutes. The patient evolved favorably with total reversion of symptoms.

In May 2012, he presented a progressive clinical picture evolving over 3 months characterized by lumbar pain, reduced strength in the lower limbs, and paraparesis in the plantar region that prevented him from performing daily tasks. The MRI revealed alterations in the spinal cord signal and morphology of the T9 and T10 vertebral bodies and intrarachial cystic formations greater than $24 \mathrm{~mm}$ in diameter at level T9-T10 compressing the dural sac and spinal cord, in addition to right paravertebral cysts in the postoperative area. (Figure 3) In August 2012, he underwent surgical intervention for the 3rd time. A posterior approach through the previous scar was performed. The membranes adhering to the dural sac were removed and a large number of vesicles were extracted, releasing the dural sac. After two months, the patient's symptoms had completely reversed and his evolution was good.

In March 2017, predominantly sensory neurological changes reappeared with neurogenic claudication and intense pain. The MRI revealed cystic formations near the right neuroforamina and right paravertebral of T8-T9 and T9-T10 compressing and displacing the spinal cord at that level, and hyperintensity of the T2 spinal cord signal from T8 to T10, compatible with compression edema. (Figure 4) The multidisciplinary team proposed anterior decompression by

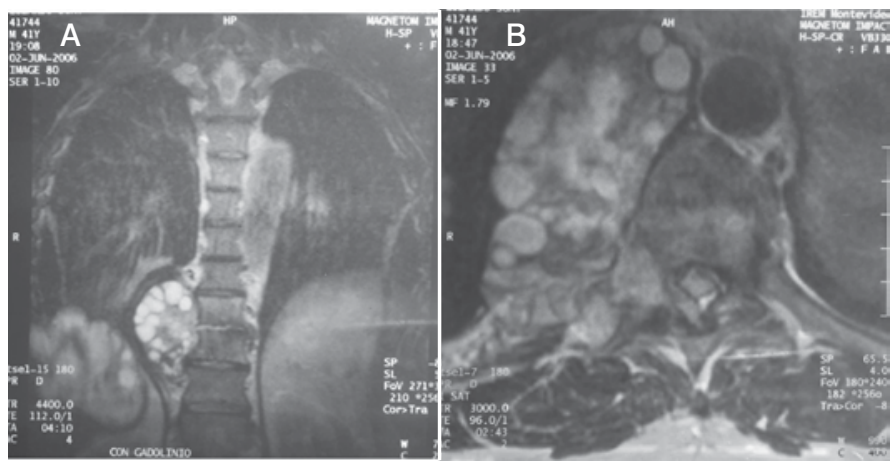

Figure 1. MRI 2006 with gadolinium: (A) coronal slice - voluminous multiseptated right paravertebral cystic lesion at levels T9 and T10; (B) axial slice compression of the spinal cord canal, vertebral bodies with altered morphology.

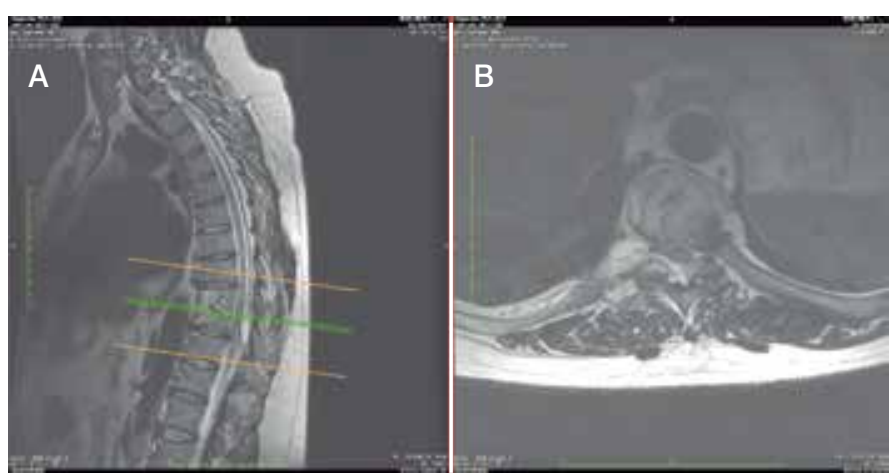

Figure 2. MRI 2010 T2 sequence: (A) sagittal slice - compromised vertebral bodies and disc; (B) axial slice - invasion of the canal via the left neuroforamen compressing the spinal cord.

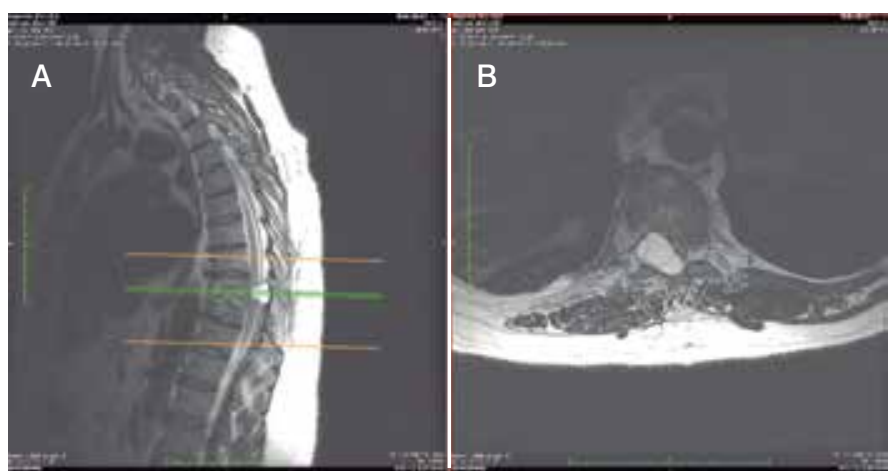

Figure 3. MRI 2012 T2 sequence: (a) sagittal slice (b) axial slice. Changes in the spinal cord signal and the morphology of the bodies of T9 and T10.

thoracotomy. With the patient in left lateral decubitus and being monitored for evoked potentials, an incision was made through the previous scar. A paravertebral tumor surrounded by a pseudocapsule was identified. The pseudocapsule was incised and a significant number of vesicles were identified. (Figure 5) Once both these and the pseudocapsule were resected, the vesicles of the spinal canal were extracted leaving the dural sac free. (Figure 6) Control was performed using an image magnifier. Once the vesicles were identified, normal flushing with hydrogen peroxide was performed. Closure was performed by planes and chest drains were left. Adjuvant albendazole treatment was initiated. The patient evolved favorably with full remission of symptoms. Three months following surgery, he was asymptomatic, performing work activities with no neurological sequelae.

\section{METHODS}

The patient authorized the surgery, photographs, and the scientific publication of his pathology and treatment via an informed consent form.

This study was approved by the Institutional Review Board as number 360 .

\section{DISCUSSION}

Hydatidosis is one of the zoonoses with higher frequency, incidence, and prevalence in our country. According to a study by the National Commission for Zoonoses, an estimated 8,000 to 10,000 Uruguayans have the disease and do not know it, with a prevalence rate of 1.3 to 3.8 cases per 1000 inhabitants. ${ }^{5}$ Since 1939 , it has been a mandatory reportable disease in our country.

Hydatidosis is caused by larvae of Echinococcus granulosus and Echinococcus multilocularis. The adult cestoid measures from 3 to $6 \mathrm{~mm}$ and lives in the jejunum of the definitive host, which in our environment is usually the dog and the eggs are expelled in the feces. Humans, the intermediary hosts, are infected by accidently ingesting the eggs. The embryos are released in the duodenum, pass through the mucous membrane, and reach the portal venous system. If they are not eliminated by the host, they continue their course and pass into the liver, which is the most common site of infestation. Sometimes, the larvae get through the first liver barrier and reach the lungs. On rare occasions, the larvae reach the arterial circulation system and affect other tissues, such as the brain, the kidneys, and the bones. The possibility of dissemination of the parasite via alternative venous paths through a portal-vertebral venous shunt and the retrograde passage of the parasite from the inferior vena cava to the retroperitoneal and epidural venous plexus has been proposed. ${ }^{6}$ Although this would explain a possible route of dissemination, it does not explain the high incidence of involvement in the thoracic spine. This suggests that the azygos vein plays a major role in the dissemination of the embryos to the spine. ${ }^{7}$

The most frequent site of infestation is the liver at $75 \%$, followed by the lungs at $15 \%$. Bone involvement is rare, found in between $0.5 \%$ and $2 \%$ of cases. Of these, the spine accounts for $50 \%$. The thoracic spine has the highest frequency at $50 \%$, followed by the lumbar and sacral spines at $20 \%$ each and the cervical spine at $10 \%{ }^{8}$ 

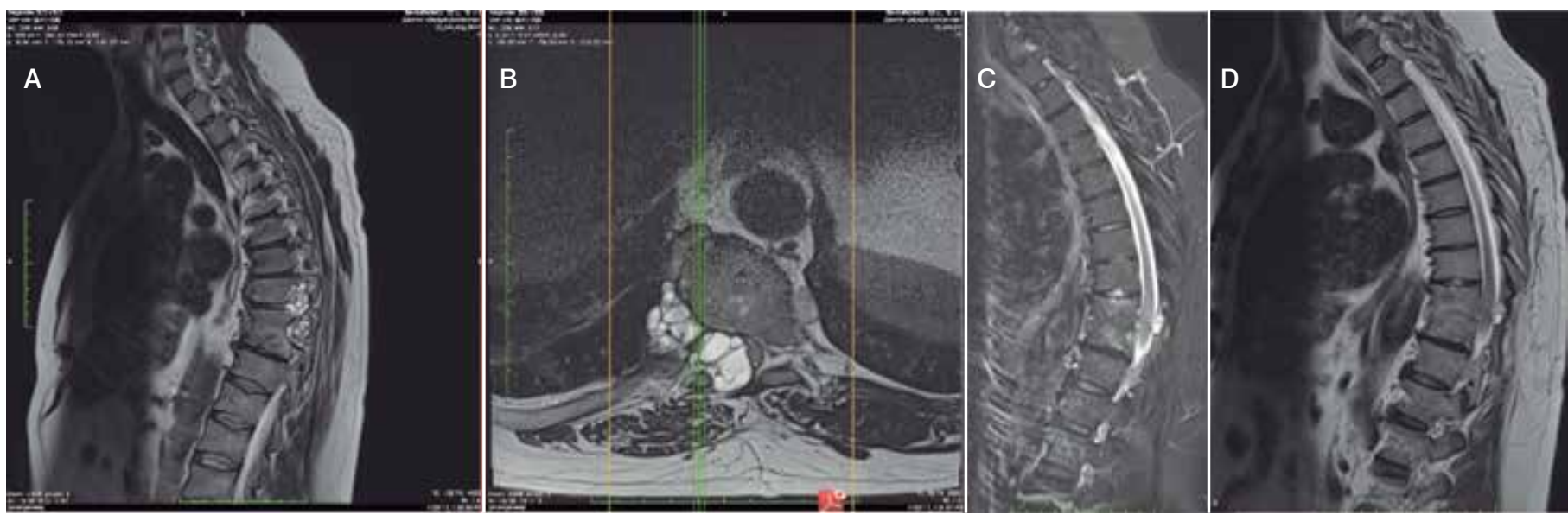

Figure 4. MRI 2017 (A) T2 sequence right parasagittal, (B) axial slice, (C) STIR sequence sagittal, and (D) T2 sequence sagittal. Cystic formations are observed next to the right neuroforamina and right paravertebral of T8-T9 and T9-T10 that compress and displace the spinal cord at that level. The hyperintensity of the signal in T2 observed in the spinal cord from T8 to T10 is compatible with compression edema.

There are two types of hydatidosis: primary, caused by hexacanth embryos, and secondary, which is a consequence of the spontaneous rupture or the accidental operative seeding of a hydatid cyst.

Bone involvement is often caused by the primary form, the secondary form being rare. ${ }^{9}$ The embryos can reach the vertebrae via arterial circulation, lodging in any part of it. The parasite usually affects the more vascularized regions, like the vertebral body, and can extend to the dural sac, the spinal cord, and the paravertebral soft tissue. Infestation of the spine usually begins as a multivesicular infiltration of the spongy bone of the vertebral body that extends to the pedicles and laminae. Cyst growth usually respects the intervertebral disc since the cysts do not compromise the periosteum, at least in the early stages.

Damage at this level is caused mainly by two mechanisms: on one hand, a mechanical effect that compresses the bone and

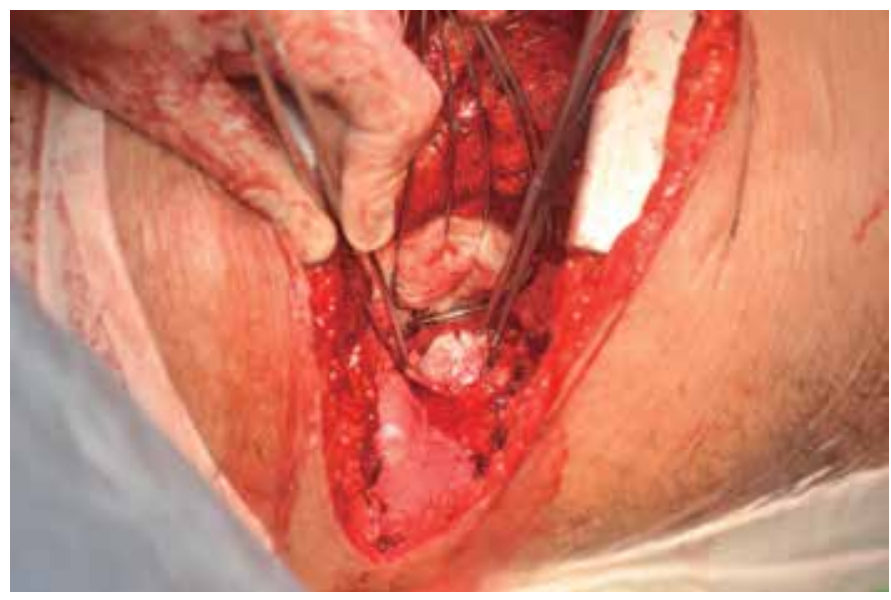

Figure 5. The pseudocapsule was incised revealing a significant number of vesicles. vascular structures, provoking necrosis from obstruction of the blood vessels; on the other hand, a cellular effect that stimulates osteoclast proliferation responsible for destruction of the bone.

Vertebral hydatidosis was classified into 5 types by Braitwaite and Lees: 1) primary intramedullary $\mathrm{CH}, 2$ ) intradural extramedullary $\mathrm{CH}, 3$ ) intraspinal extradural $\mathrm{CH}$, 4) vertebral hydatidosis, and 5) paravertebral hydatidosis. They also described the so-called dumbbell formation, which occurs when the vesicles inside the spinal canal extend outside of the neuroforamen, which corresponds to the case reported. ${ }^{10}$

Histologically, the hydatid cyst has two layers, one internal, the germinal, and one external, the acellular, that measures $60-70 \mu \mathrm{m}$. The granulomatous reaction of the host provokes the formation of a third layer called the adventitia. We did not find this last layer in the bone. The liquid content is colorless, crystalline, and transparent." The germinal layer gives rise to vesicles in which protoscolices develop, with 4 suckers and a crown of hooks (scolices). These vesicles can be found adhered to the wall or free-floating in the liquid. The remains of the membrane and the protoscolices together make up the so-called "hydatid sand". The size of the cyst can vary from a few millimeters to more than $15 \mathrm{~cm} .^{11}$

A vertebral hydatidosis diagnosis is generally a late one. Due to slow growth, the disease is expressed clinically when in advanced stages. The clinical manifestations are nonspecific and a consequence of the effect of the compression. Spinal cord compression is the classic presentation of this disease, reported in between 47 and $73 \%$ of cases, followed by pain. ${ }^{12}$ Other less common clinical manifestations are radicular pain, neurogenic claudication, and, less frequently, sphincter changes.

The low frequency of this disease makes it necessary to consider other differential diagnoses such as Pott disease, bacterial or mycotic osteomyelitis, chordoma, sarcoma, and arachnoid cysts, among others. The diagnosis is based on clinical, imaging, and anatomopathological data, supported by serology, especially ELISA, which has a sensitivity of approximately $86 \%$ and a specificity of $93 \% .{ }^{13}$

The complementary imaging studies used are simple radiography, $\mathrm{CT}$, and MRI. The radiograph is nonspecific and does not provide any
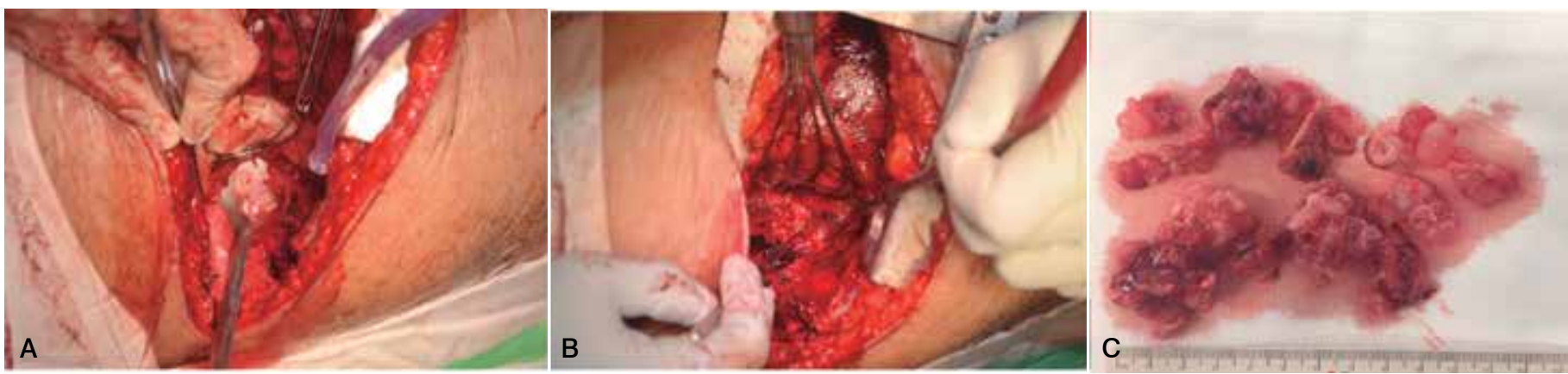

Figure 6. (A) resection of the vesicles, $(B)$ exploration of the canal $(C)$ material obtained, with multiple ruptured vesicles observed 
etiological information. The radiological findings are characterized as presenting a single or multiple osteolytic cystic lesions of an expansive nature, poorly delimited, and without periosteal reaction. ${ }^{14}$

We use the CT to quantify the destructive changes at the bone level. The MRI is the study of choice since it allows the visualization of characteristic images, being a diagnostic pillar. The greatest advantage it provides is that it allows an accurate assessment of the relationship between the cysts and the spinal cord, essential to the development of the surgical plan.

Fahl et al. described the characteristics of the hydatid cyst in MRIs. They detailed the characteristics of intradural and extradural cysts. T1 sequences are particularly sensitive for identifying hydatid cysts and their relation to neighboring structures. In T1, the multilocular cyst has a signal intensity similar to muscle and in T2 the offspring cysts are hyperintense. ${ }^{15}$

Several authors state that hyperintense cystic content indicates cyst viability, while a decrease in the signal of the cyst and an increase in the signal of the walls indicate that the cyst is in the process of degeneration.

The treatment of this pathology is both clinical and surgical. The difference between this and other locations is that, in the vertebral hydatid cyst, complete resection of the cysts is not possible because of the complications that this entails. In general, decompression of the spinal canal by means of laminectomy is the most used procedure, accompanied by exeresis of the cysts. ${ }^{15,16}$

Stabilization by means of instrumentation should be considered in cases of mechanical instability. This can be caused by the need for extensive releases in order to free the spinal canal due to the lytic involvement the disease. A study that conducted a systematic review of this condition showed that laminectomy was performed in more than $90 \%$ of cases. ${ }^{17}$ In cases where there was vertebral body collapse and involvement of the spinal canal, the patient may benefit from an anterior or anterolateral approach vertebrectomy and placement of a cage for circumferential stabilization. ${ }^{18}$

The location and extension of the lesion are the main variables in determining the surgical approach. Thus, in the case presented, the first instance of intervention was an anterior approach thoracotomy and the second two opportunities were posterior approaches given that the compression was predominant in this sector. The final instance of intervention was once again by anterior approach, since the greatest volume of vesicles and resulting compression was anterior.

Multiple alternative fixation methods have been described, such as pedicle screws and titanium cages combined with cement and autologous graft, among others, with variable results. ${ }^{19}$

These procedures can cause serious complications that can compromise the life of the patient. The walls of the cysts can rupture from minimal surgical trauma or spontaneously, causing recurrence at the local level or even the development of an anaphylactic reaction from contact with the cystic liquid. ${ }^{20}$

Rupture of the cyst is not infrequent in vertebral hydatidosis since they are delimited by bony, rigid structures in reduced spaces. Rupture rates as high as $44 \%$ have been reported, mainly for extradural cysts. ${ }^{21,22}$

Antihelminthic drugs such as albendazole or mebendazole are used in conjunction with surgical treatment. The duration of postoperative use of these drugs is debated. Within the benzimidazole family, albendazole has demonstrated satisfactory results in multiple studies. ${ }^{23}$

Although cases have been cured, one of the objectives is also to prevent recurrence and dissemination in case of rupture of the cyst. ${ }^{23}$ Several authors suggest irrigation of the wound with a hypertonic saline solution after resection of the cysts. The objective is the destruction of the parasite osmotically, however, this has not been proven for vertebral hydatidosis.

The main complication of vertebral $\mathrm{CH}$ is recurrence, with rates from 30 to $89 \% .{ }^{24,25}$ This is one of the main reasons why this pathology has a poor prognosis. However, there are few studies that assess long-term survival.

\section{CONCLUSIONS}

Vertebral hydatidosis is one of the differential diagnoses when imaging presents osteolytic cysts with medullary compression, especially in endemic areas like our country. It is a complex pathology that requires a multidisciplinary approach involving a traumatologist specialized in spine surgery, a neurosurgeon, a thoracic surgeon, and a parasitologist. Treatment is clinical-surgical and generally involves decompression of the spinal canal and resection of the cysts via anterior, posterior, or combined approach, accompanied by antihelminthic drugs. Stabilization is performed mainly in the case of instability. The treatment is rarely curative and the recurrence rate is high, generally requiring multiple surgeries. The prognosis is poor because of the characteristics already mentioned.

All authors declare no potential conflict of interest related to this article.

CONTRIBUTION OF THE AUTHORS: Each author made significant individual contributions to this manuscript. All of the authors participated actively in the discussion of the results and in the review and approval of the final work. JMV (0000-0001-8063-3091)* and SS (0000-0003-1423-5540)* were the main contributors to the writing of the manuscript. JMV, SS, FG (0000-0001-6163-1402)*, and NG $(0000-0003-3830-5902)^{\star}$ participated in the surgeries and patient follow-up and compiled the clinical data. FG, NG, and SS conducted the bibliographical research. All authors reviewed the manuscript and contributed to the intellectual concept of the study. ${ }^{*}$ ORCID (Open Researcher and Contributor ID).

\section{REFERENCES}

1. Turnes AL. La Hidatidosis humana: una enfermedad olvidada. Órgano oficial de la comisión zoonosis del Uruguay. Zoonosis.2011:2:4-5

2. Montúfar-Valer A, HuapayaJurado FL Características clínicas, radiológicas y laboratoriales de pacientes con hidatidosis hepática en un hospital de referencia nacional Lima 1997-2010. Rev Gastroenterol Perú. 2014;34(3):203-9.

3. Neumayr A, Tamarozzi F, Goblirsch S, Blum J, Brunetti E. Spinal Cystic Echinococcosis - A Systematic Analysis and Review of the Literature: Part 2. Treatment, Follow-up and Outcome. PLoS NeglTrop Dis. 2013;7(9):e2458.

4. Dévé F L'Echinococcose osseuse. Montevideo: Monteverde y Cia;1948.

5. Irabedra P, Elola S. Estrategias para la vigilancia, control y prevención de la equinococosis quisitcas en áreas de riesgo. Órgano oficial de la comisión zoonosis del Uruguay. Zoonosis.2011;2:14-16.

6. Pamir MN, Ozduman K, Elmaci I. Spinal hydatid disease. Spinal Cord. 2002;40(4):153-60

7. Sener RN, Calli C, Kitis O, Yalman O. Multiple, primary spinal-paraspinal hydatid cysts. Eur Radiol. 2001:11(11):2314-6.

8. Kafaii A, Al-Zain T, Lemcke J, Al-Zain F. Spinal manifestation of hydatid disease: a case series of 36 patients. World Neurosurg. 2013;80(5):620-6.

9. Islekel S, Ersahin Y, Zileli M, Oktar N, Oner K, Ovul I, et al. Spinal hydatid disease. Spinal Cord. 1998;36(3):166-70.

10. Patel D1, Shukla D. Back bugged: A case of sacral hydatid cyst. J Neurosci Pract. 2010;1(1):43-5

11. Braithwaite PA, Lees RF. Vertebral hydatid disease: radiological assessment. Radiology. 1981;140(3):763-6.

12. Hegglin $D$, Bontadina F, Deplazes P. Human-wildlife interactions and zoonotic transmission of Echinococcus multilocularis. Trends Parasitol. 2015;31(5):167-73.

13. Keshmiri M, Baharvahdat $H$, Fattahi $S H$, Davachi B, Dabiri $\mathrm{RH}$, Baradaran $\mathrm{H}$, et al. Albendazol ver- sus placebo en el tratamiento de la equinococcosis. Trans RSoc Trop Med Hyg. 2001;95(2) 190-4 14. Munoz P. Diagnóstico y tratamiento de la hidatidosis. Rev chil infectol. 2007;24(2):153-4.

15. Resnick D. Osteomielitis, artritis séptica e infecciones de partes blandas: organismos. In: Resnick D, editor. Huesos y articulaciones en imagen. Madrid: Marbán; 2001. p. 684-716. 16. Song X, Liu D, Wen H. Diagnostic pitfalls of spinal echinococcosis. J Spinal Disord Tech 2007;20(2):180-5

17. Pesudo JV, Laguía M, Roldán P, Pallardó Y, Cerdá M, Blasco C, et al. Equinococosis vertebral: a propósito de un caso. Neurocirugía. 1998:9(3):199-272

18. Neumayr A, Tamarozzi F, Goblirsch S, Blum J, Brunetti E. Spinal Cystic Echinococcosis - A Systematic Analysis and Review of the Literature: Part 2. Treatment, Follow-up and Outcome. PLoS Negl Trop Dis. 2013;7(9):e2458.

19. Kaloostian PE, Gokaslan ZL. Spinal Hydatid Disease: A Multidisciplinary Pathology. World Neurosurg. 2015;83(1):52-3.

20. Yildiz Y, Bayrakci K, Altay M, Saglik Y. The use of polymethylmethacrylate in the management of hydatid disease of bone. J Bone Joint Surg Br. 2001;83(7):1005-8.

21. Neumayr A, Troia G, de Bernardis C, Tamarozzi F, Goblirsch S, Piccoli L, et al. Justified concern or exaggerated fear: the risk of anaphylaxis in percutaneous treatment of cystic echinococcosis-a systematic literature review. PLoS Negl Trop Dis. 2011;5(6):e1154.

22. Altinors N, Bavbek M, Caner HH, Erdogan B. Central nervous system hydatidosis in Turkey: a cooperative study and literature survey analysis of 458 cases. J Neurosurg. 2000;93(1):1-8.

23. García-Vicuña R, Carvajal I, Ortiz-Garcia A, López-Robledilo JC, Laffón A, Sabando P.Primary solitary Echinococcosis in cervical spine. Postsurgical successful outcome after long-term albendazole treatment. Spine (Phila Pa 1976).2000;25(4):520-3.

24. Lam KS, Faraj A, Mulholland RC, Finch RG. Medical decompression of vertebral hydatidosis. Spine (Phila Pa 1976). 1997:22(17):2050-5. 